\title{
Hydrogen-bonding interactions in crown-(thio)urea complexes with anions, chemical warfare agents and simulants
}

Hannah Cave ${ }^{1}$, Jayne A. Ede ${ }^{2}$, Mark R. Sambrook², Howard Dodd ${ }^{1}$, Flavia Fucassi $^{1}$, Alexander S. Cragg ${ }^{1,3}$, Adam H. Lansley ${ }^{1}$ and Peter J. Cragg ${ }^{1 *}$ ${ }^{1}$ School of Pharmacy and Biomolecular Sciences, Huxley Building, University of Brighton, Brighton BN2 4GJ, UK.

${ }^{2}$ CBR Division, Defence Science and Technology Laboratory (Dstl) Porton Down, Salisbury, SP4 OJQ, UK.

${ }^{3}$ School of Physical Sciences, University of Kent, Canterbury, CT2 7NH, UK

*Corresponding author, email: P.J.Cragg@brighton.ac.uk 


\title{
Hydrogen-bonding interactions in crown-(thio)urea complexes with anions, chemical warfare agents and simulants
}

\author{
Benzocrown ethers incorporating phenyl and nitrophenyl urea and thiourea \\ moieties were synthesised. Both the nitrophenyl urea and thiourea derivative \\ gave a fluoride-specific colorimetric response but only the urea derivative bound \\ the organophosphonate nerve agent simulants dimethyl methylphosphonate \\ (DMMP) and diisopropyl methylphosphonate (DIMP). This suggested an \\ application as sensors for the nerve agents sarin, soman and cyclosarin which \\ release fluoride upon hydrolysis. Although no fluoride-induced response was \\ observed in the UV-visible spectrum, binding to soman was determined by ${ }^{1} \mathrm{H}$ \\ NMR. DFT computational simulations suggested that the two crowns adopt \\ different conformations in which both can bind fluoride but only the urea \\ derivative can bind DMMP, DIMP and soman. The results show that, for this \\ system, simulant- and soman-binding behaviours are in good agreement.
}

Keywords: Chemical warfare agents; simulants; macrocycles; colorimetric sensors; hydrogen bonding

\section{Introduction}

Despite the 1993 Chemical Weapons Convention banning the preparation and stockpiling of nerve agents which could have military uses, these chemical warfare agents (CWAs) persist around the world $(1,2,3)$. The development of novel and innovative detection and destruction methods therefore continues to present a number of technical challenges $(4,5)$.

Recent supramolecular approaches to detecting and/or disclosing the presence of CWAs include the use of hydrogen bond donor-rich compounds to mediate noncovalent association. These include the use of bis-phenol oligosiloxane copolymers to detect hydrogen bond accepting nerve agent simulants (lower toxicity analogues, also known as mimics and surrogates) such as dimethyl methylphosphonate (DMMP) (6). Gale and co-workers presented a host system based upon a central urea moiety, with 
two hydrogen bond donors, linked to up to six additional indole or amide hydrogen bond donor sites that resulted in downfield chemical shift perturbations in the ${ }^{1} \mathrm{H}$ NMR in the presence of pinacolyl methylphosphonofluoridate, also known as soman and hereafter referred to as GD, in organic solvents, which is typical of the formation of hydrogen-bonds (7). This hydrogen-bond mediated interaction was later exploited in responsive supramolecular gels (8) and in investigations into anion, simulant and GD recognition by a series of neutral and charged receptors (9). More recently, Ha et al. utilised a series of structurally related thioureas in a quartz microbalance-based approach to CWA detection, using the simulant DMMP (10). These results all indicate that the exploitation of hydrogen bond interactions may be a plausible recognition pathway for CWAs and that increasing the number of hydrogen bond donors increases the CWA binding affinity, as might be expected. Combining hydrogen bond donor molecules with thiourea derived organocatalysts has also been shown to facilitate the hydrolysis of the simulants diisopropyl fluorophosphate (DFP) and diethyl cyanophosphonate (DECP) (11). ${ }^{1} \mathrm{H}$ NMR was used to confirm that host-guest complexes had formed and it was suggested that the binding of the guest molecule through hydrogen bonding increased the electrophilic nature of the phosphorus centre, making it more susceptible to nucleophilic attack.

GA

Figure 1. Organofluorophosphonate nerve agents and commonly used simulants 
Alternative detection methods include the reaction of DECP with a salicyloxime derivative of BIODIPY (4,4-difluoro-4-bora-3a,4a-diaza-s-indacene). This system targets the cyanide-releasing GA and its simulant DECP leading to an increase in fluorescence intensity caused by the quenching of photoinduced electron transfer. Two other CWA simulants, diethyl methylphosphonate (DEMP) and diethyl chlorophosphate (DCP), displayed no such effects, as expected (12). One unifying feature of all these examples is that detection requires laboratory instrumentation. While many methods for fluoride determination exist (13-16) we wished to develop sensing molecules which gave a visual response at high concentrations but would also be suitable for detecting lower concentrations by spectrophotometric methods. Herein we describe a crown ether derivative incorporating a chromophore to allow detection of GD by visual inspection though its chromogenic response to fluoride formed in situ upon hydrolysis.

Nerve agents GB, GD and GF (Figure 1) share a similar decomposition mechanism in which fluoride is released upon hydrolysis (17). GD hydrolysis leads to the generation of pinacolylmethyl phosphonate (PMP) and fluoride in the first hydrolysis step and methylphosphonic acid in the second. Both processes are slow at neutral $\mathrm{pH}$ but accelerate under acidic or, more usually, basic conditions where hydrolysis is rapid. Given that fluoride is rarely found in the environment, its detection in the first hydrolysis step could form the basis of a sensor for organofluorophosphonates, however, to prove that the source of the fluoride is a CWA it would also be necessary to capture the organophosphonate by-product of hydrolysis. We have investigated the complexation abilities of crown ether derivatives with the potential to signal the presence of fluoride-releasing nerve agents. Other urea and thiourea crown ether derivatives have been prepared to detect anions and ion pairs (1827) but this work represents the first example where nerve agents have been targeted. In 
particular we wished to probe the responses of the urea and thiourea derivatives to GD and its commonly used simulants DMMP and diisopropyl methylphosphonate (DIMP). The response of GD was investigated to determine if it bound in the same manner as the simulants. The ability to understand the correlation between CWA and simulant binding behaviour in a wide range of host-guests systems will be valuable to better understand simulant behaviour and to facilitate further research where access to actual CWAs is not feasible. Studies that allow for the generation of such data are limited, but do include recognition processes mediated by hydrogen bonding (9), as well as, for example, hydrophobic inclusion (28). Despite the commonality of the hydrogen bond accepting $\mathrm{P}=\mathrm{O}$ group across nerve agent CWAs and simulants, differences in binding behaviour can be significant and simulant selection can be challenging (29-31).

\section{Synthesis of benzocrown ether derivatives and their interactions with anions}

Barboiu’s 4-phenylurea-benzo-15-crown-5 (1a) has been reported as an excellent transport agent for sodium salts (32). For our purposes the crown motif could also bind the CWA at the point of hydrolysis while the urea/thiourea motif is known to respond to fluoride through deprotonation (33-35). We therefore prepared 1a and three further potential molecular sensors incorporating a benzo-15-crown-5 receptor and substituents comprised of phenylthiourea (1b), 4-nitrophenylurea (1c) or 4-nitrophenylthiourea (1d).
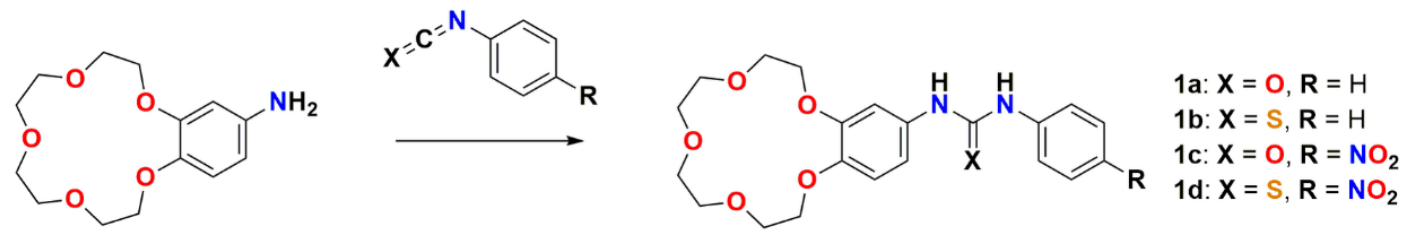

Scheme 1: Synthesis of benzocrown ethers 1a-d 
Addition of tetrabutylammonium halides in acetonitrile had no effect on 1c with the exception of the fluoride salt which gave a yellow-green solution (Figure 2). The thiourea derivative, $\mathbf{1 d}$, gave a noticeable response to other halides in addition to fluoride due to the greater acidity of the thiourea moiety leading to more facile deprotonation (36, 37).
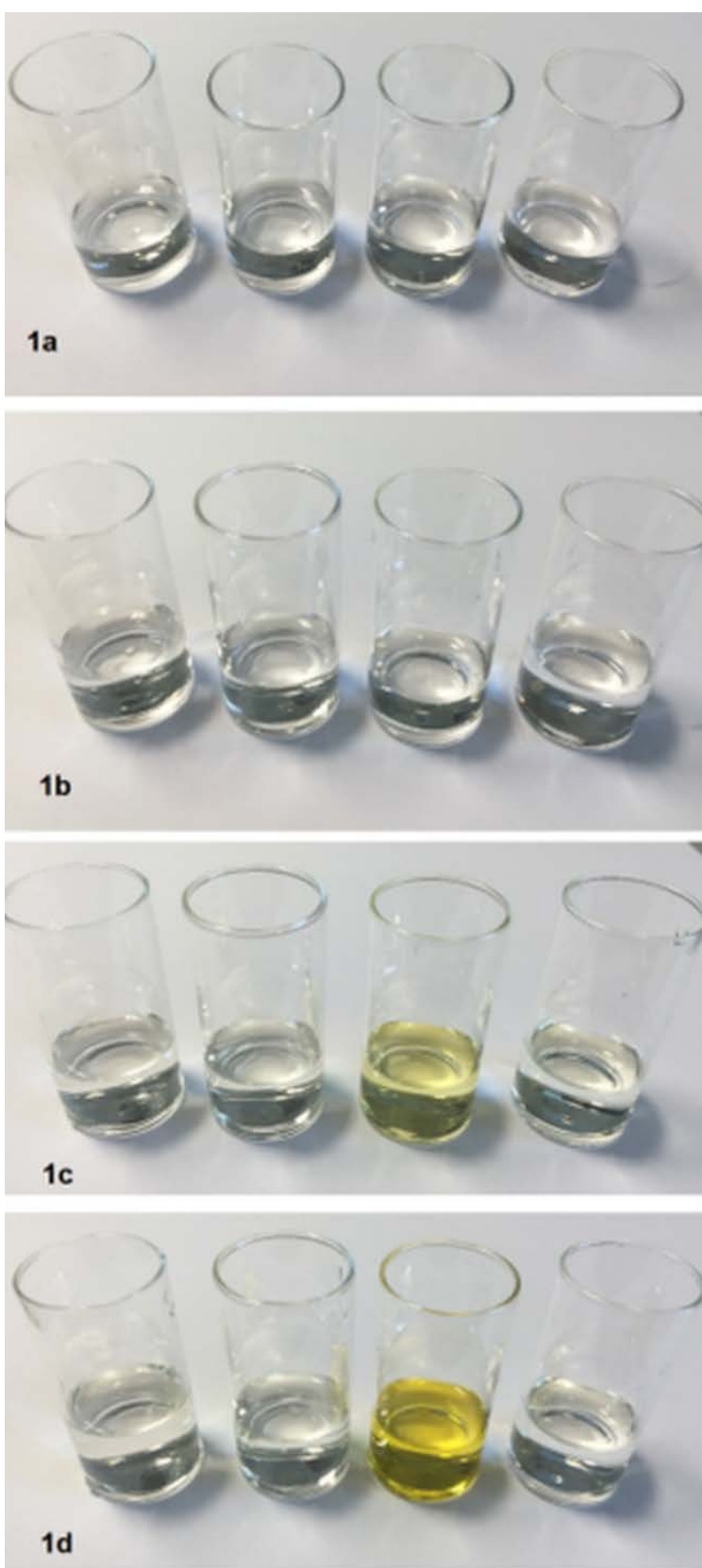

Figure 2: Responses of $\mathbf{1 a - d}$ to $\mathrm{Bu}_{4}^{\mathrm{t}}{ }_{4} \mathrm{~N}$ halides in acetonitrile at $20^{\circ} \mathrm{C}$ : (left to right) $\mathrm{I}^{-}$, $\mathrm{Br}^{-}, \mathrm{F}^{-}, \mathrm{Cl}^{-}$ 
As 1c gave a colorimetric response to fluoride over other halides, further studies were undertaken to determine the specificity of its response towards anions more generally. Of those tested, only fluoride, hydroxide and acetate gave a visually detectable response (Figure 3) and, of these, fluoride gave a yellow-green colour with the false positives being orange or pale yellow. The fluoride complex solution turns orange-yellow after 24 hours by which time deprotonation is presumably complete. Given the ubiquity of hydroxide and acetate it is fortunate that the colours their complexes display are visibly different from the yellow-green $\left(\lambda_{\max }=367 \mathrm{~nm}\right)$ response elicited by fluoride (Figures 3 and 4).

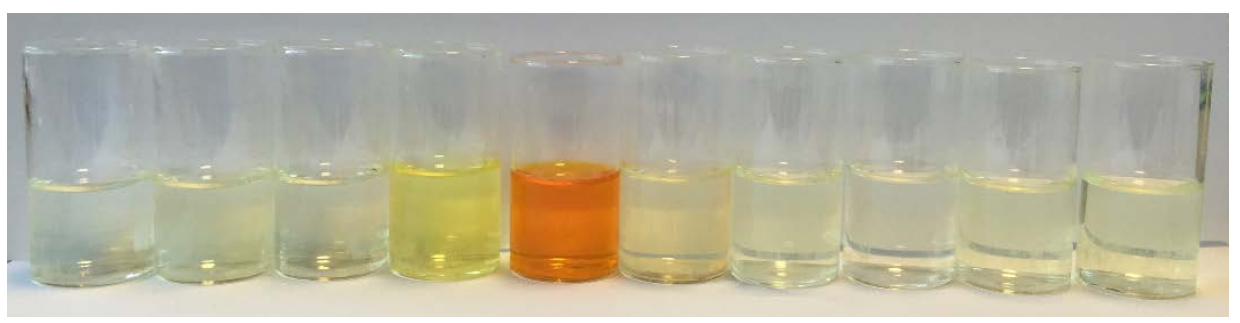

Figure 3: Response of $1 \mathrm{c}$ to anions in acetonitrile at $20^{\circ} \mathrm{C}$ : (from left) $\mathrm{I}^{-}, \mathrm{Cl}^{-}, \mathrm{Br}^{-}, \mathrm{F}^{-}$, $\mathrm{OH}^{-}, \mathrm{CH}_{3} \mathrm{CO}_{2}^{-}, \mathrm{HSO}_{3}^{-}, \mathrm{BF}_{4}^{-}, \mathrm{NO}_{3}^{-}, \mathrm{PO}_{4}^{3-}$

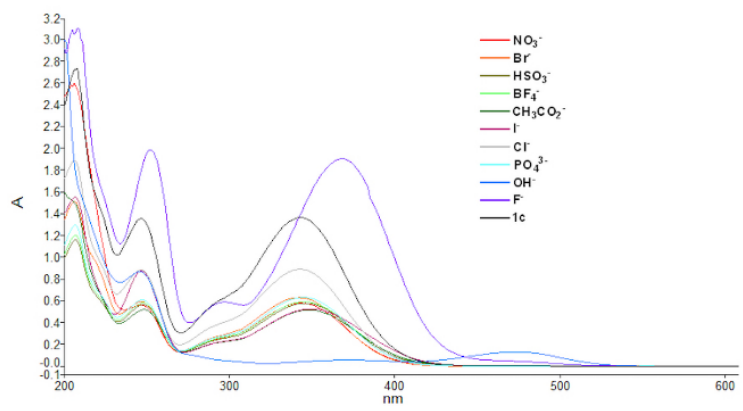

Figure 4: UV-visible spectra of $\mathbf{1 c}$ with ${ }^{\mathrm{n}} \mathrm{Bu}_{4} \mathrm{~N}^{+}$salts in acetonitrile at $20{ }^{\circ} \mathrm{C}$

Having demonstrated that $\mathbf{1 c}$ gave an observable visible response to fluoride the next objective was to investigate the interactions with simulants using ${ }^{1} \mathrm{H}$ NMR. Tests 
of the non-nitrated derivatives showed significant shifts of the urea protons of 1a upon addition of increasing amounts of DMMP, although the effect was much less for $\mathbf{1 b}$ (Supplementary information, Figs. S13 and S14). ${ }^{1} \mathrm{H}$ NMR titration of 1c with DMMP showed more significant shifts of the urea protons presumably due to the presence of nitro groups and, again, the effect on 1d was greatly reduced (Supplementary information, Figs. S15 and S16). This behaviour indicated that the simulants were complexed by compounds 1a-d through the formation of hydrogen bonds, but that this occurs at the same site where fluoride was also expected to bind. These results suggest that, if CWAs were bound and hydrolysed, there would be competition for the same site.

Density functional (B3LYP/6-31G*) computational simulations were developed using a gas phase model to give insights into how fluoride, GD and the simulants may bind to 1c and 1d (Figure 5). Hydrolysis and subsequent binding of the two species is assumed to occur through complementary $\mathrm{N}-\mathrm{H} \cdots \mathrm{F}^{-}$interactions for fluoride and a combination of $\mathrm{O}-\mathrm{H} \cdots \mathrm{O}_{(\text {crown) }}$ and hydrophobic interactions for PMP. For $\mathbf{1 c}$ the interaction between the hydrogen bond acceptor phosphonate oxygen group and the hydrogen bond donating urea protons is in agreement with ${ }^{1} \mathrm{H}$ NMR data.
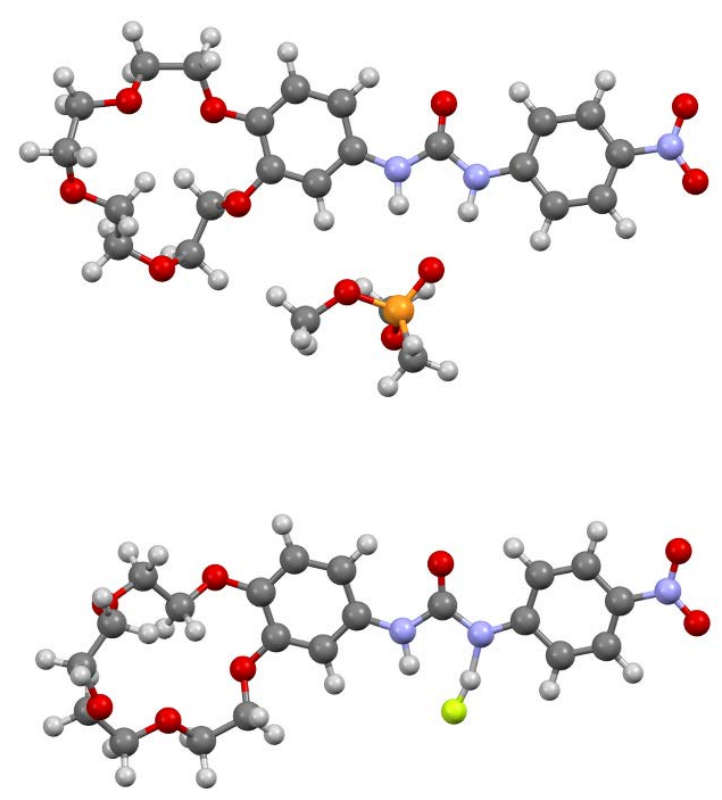
Figure 5: Computational simulation (DFT/B3LYP/6-31G*, gas phase) of the binding between 1c and DMMP (top) and $\mathrm{F}^{-}$(bottom)

Addition of fluoride resulted in the removal of one urea proton and the formation of a hydrogen fluoride interaction with a bond distance of $1.064 \AA$, slightly longer than the $0.93 \AA$ expected for the covalent H-F bond but significantly shorter than the $1.60 \AA$ found for strong intermolecular $\mathrm{H}-\mathrm{F}^{\cdots}{ }^{\cdots} \mathrm{H}-\mathrm{F}$ hydrogen bonds (38). Of greater interest was the simulation of 1c with the GD hydrolysis products, PMP and fluoride, where the latter bound to the urea and the phosphonate bound to the crown moiety of $\mathbf{1 c}$ through a combination of hydrogen bonding to an ether oxygen and hydrophobic interactions (Figure 6).

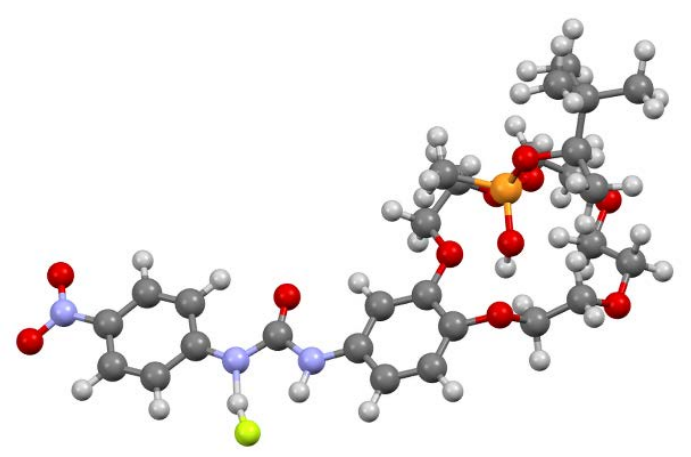

Figure 6: Computational simulation (DFT/B3LYP/6-31G*, gas phase) of the binding between 1c and GD hydrolysis products $\mathrm{F}^{-}$and PMP

This suggests that 1c should bind to both hydrolysis products of GD and signal the potential presence of nerve agent colorimetrically through the urea-fluoride interaction as shown in Scheme 2.

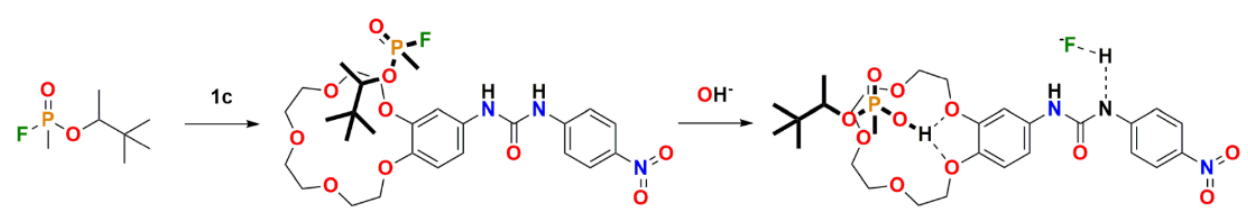


Scheme 2: Proposed hydrolysis and binding between GD and 1c

To investigate if GD was bound by $\mathbf{1 c}$ and $\mathbf{1 d}$ as predicted, solutions of the ligands were dissolved in acetonitrile and two molar equivalents of 95\% purity GD were added. Using UV-vis absorption spectroscopy no changes in wavelength were observed indicating that neither GD nor any traces of PMP affected the absorbance maximum (Supplementary information, Fig. S17 and S18). Addition of water, which may be expected to further liberate fluoride, also had no significant effect. It is possible that not enough hydrolysis occurred to give a detectable peak or that any HF generated did not dissociate in acetonitrile to give sufficient detectable fluoride. As shifts had been observed in the NMR when the simulant DMMP was added to solutions of $\mathbf{1 c}$ and $\mathbf{1 d}$, similar titration experiments were attempted initially with the simulant DIMP (Figure 7) and then with GD (Figure 8) in $\mathrm{CDCl}_{3}$. In the case of DIMP, chemical shift perturbations of the NH host protons were very small, suggesting the formation of only very low affinity complexes. Larger perturbations were observed with both the N-H and aromatic $\mathrm{C}-\mathrm{H}$ in the case of the urea compound, $\mathbf{1 c}$, than for the thiourea compound, $\mathbf{1 d}$, potentially indicating higher affinity and complex formation. The NH protons were not clearly resolved and rapidly broadened into the baseline, which is a common observation in H-bonding studies. In the case of GD, no chemical shift perturbations were observed in the case of the thiourea receptor, 1d, indicating a lack of complex formation. 


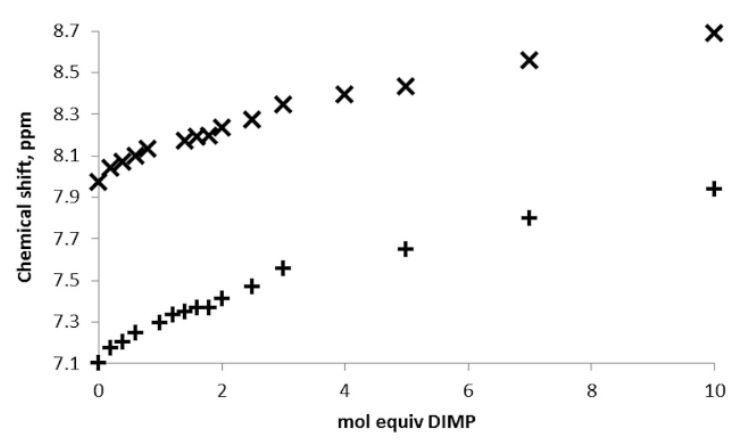

Figure 7: ${ }^{1} \mathrm{H}$ NMR shifts for the NH proton environments of $1 \mathbf{c}$ upon addition of DIMP $\left(\mathrm{CDCl}_{3}, 298 \mathrm{~K}\right)$

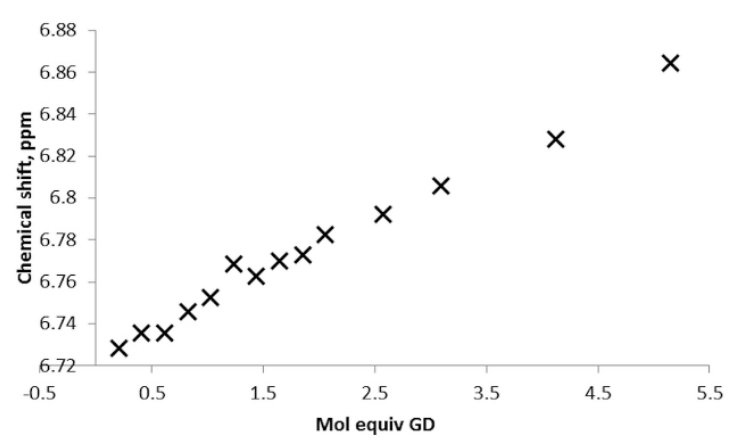

Figure 8: ${ }^{1} \mathrm{H}$ NMR shifts for GD binding to $1 \mathrm{c}$ in $\mathrm{CDCl}_{3}$ (CH proton shown)

Fitting of ${ }^{1} \mathrm{H}$ NMR titration data to a 1:1 model using EQNMR (39) was indicative of low affinity complexes. In the case of the DIMP titration with 1c, fitting of both $\mathrm{NH}$ proton environments did allow for the determination of approximate binding constants of $K_{\text {assoc }}=85 \pm 15 \mathrm{M}^{-1}$ and $107 \pm 20 \mathrm{M}^{-1}$, which are in reasonable agreement given the low affinity of the complex. In the case of the GD titration, the $\mathrm{CH}$ chemical shift data data could not be refined sufficiently to furnish a quantitative value but was suggestive of $K_{a s s o c}<50 \mathrm{M}^{-1}$.

To understand why $1 \mathbf{c}$ interacts with ${ }^{\mathrm{n}} \mathrm{Bu} 4 \mathrm{NF}$, DMMP, DIMP and GD but 1d only responds to fluoride, models of the complexes were generated (Figure 9). Conformational analysis showed that while 1c adopted an extended geometry in the gas phase, 1d preferentially adopted a folded geometry. These different geometries allowed 
both molecular hosts to bind fluoride through $\mathrm{N}-\mathrm{H}^{\cdots} \cdot \mathrm{F}^{-}$interactions. Upon introduction of GD and the simulants, $\mathbf{1 c}$ bound all species, however, $\mathbf{1 d}$ remained in a folded geometry throughout, blocking the formation of non-covalent interactions that would lead to complex formation, in agreement with both the ${ }^{1} \mathrm{H}$ NMR and UV-visible data for 1c and 1d. Similar observations were reported by Gale and co-workers, in which comparison of urea and thiourea host molecules with regard to anion binding indicated that the presence of the larger sulfur atom decreased the likelihood of the host adopting a planar conformation $(40,41)$.
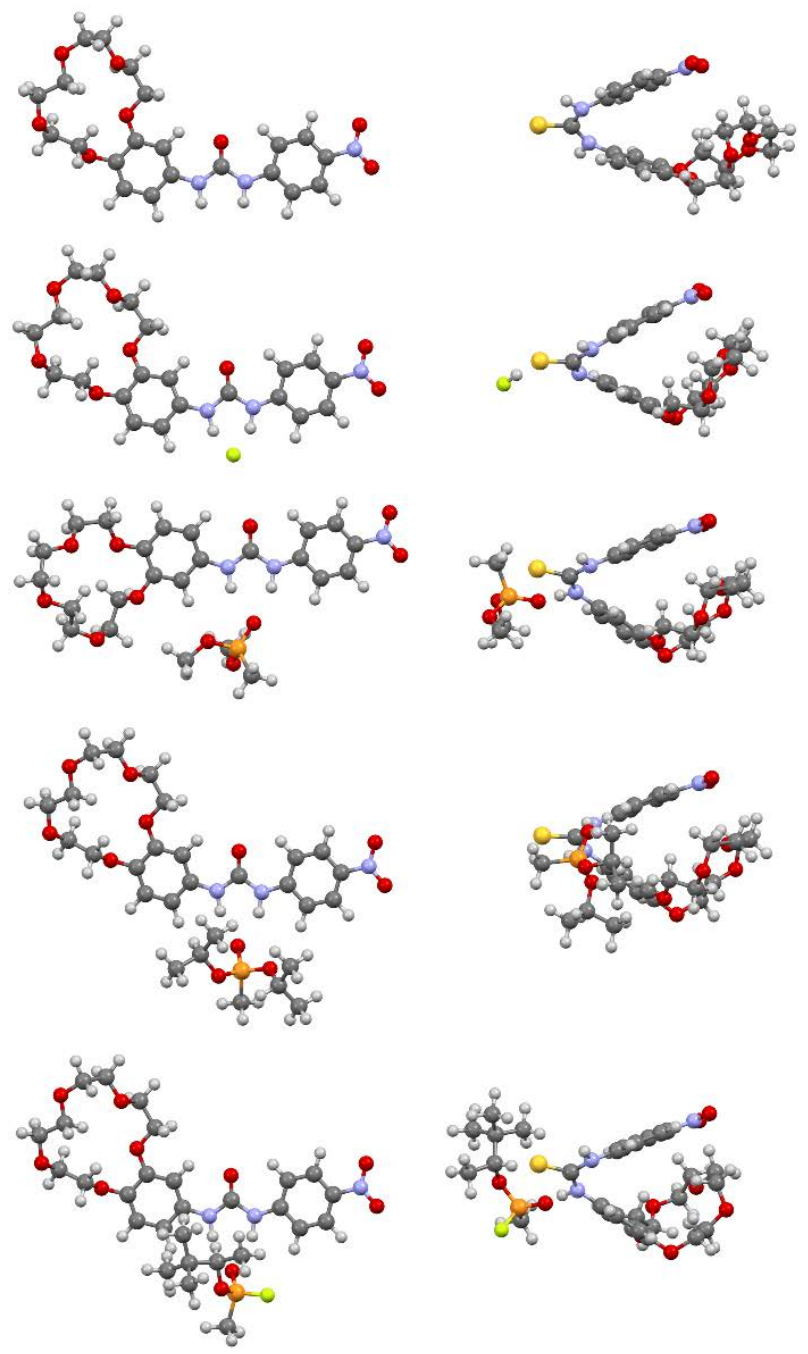

Figure 9: Computational simulation (DFT/B3LYP/6-31G*, gas phase) of 1c (left) and 1d (right) and in complexes with ${ }^{\mathrm{n}} \mathrm{Bu}_{4} \mathrm{NF}$ (with ${ }^{\mathrm{n}} \mathrm{Bu}_{4} \mathrm{~N}^{+}$removed for clarity), DMMP, DIMP and GD 


\section{Conclusions}

We have shown that, for the functionalized macrocycles studied, the thioureacontaining derivative only allows fluoride to bind whereas its urea-containing analogue also interacted with DMMP, DIMP and, importantly, GD. Computational simulations suggested that this is a result of conformational changes within the molecular structure when progressing from the urea to the thiourea derivative. This may have implications for host design as simply increasing the acidity of the hydrogen bond donating protons may not always result in higher affinity complexes being formed. Both of the nitrocontaining compounds (1c and $\mathbf{1 d )}$ gave a colorimetric response to fluoride which was visibly different to all other anions investigated. The lack of change in the UV-vis spectrum indicated that GD hydrolysis did not occur under the conditions employed, however, the concentration-dependent shifts in the ${ }^{1} \mathrm{H}$ NMR for $\mathbf{1 c} \cdot \mathrm{GD}$ are consistent with binding through the interactions shown in the DFT prediction. Additional information on the correlation of simulant and CWA behaviour, specifically in the context of hydrogen bonded complexes, has been furnished. These results will be useful to supplement the existing, limited, data available in such studies, and potentially in the wider consideration of simulant selection (42). Having demonstrated GD binding by 1c we are currently developing methods of promoting CWA hydrolysis to allow chromogenic detection by similar sensing systems.

\section{Experimental}

Unless otherwise stated, all materials and solvents were from Sigma-Aldrich (Gillingham, Dorset, UK). NMR spectra were recorded either on a Bruker Avance-400 instrument at 400 and $90 \mathrm{MHz}$ for ${ }^{1} \mathrm{H}$ and ${ }^{13} \mathrm{C}$ respectively, or $9.4 \mathrm{~T}$ using a Bruker AVHD $400 \mathrm{MHz}$ spectrometer equipped with a $5 \mathrm{~mm} \mathrm{BBFO+} \mathrm{probe} \mathrm{head} \mathrm{at} \mathrm{a}$ temperature of $293 \mathrm{~K} .{ }^{1} \mathrm{H}$ NMR was recorded at $400.16 \mathrm{MHz}$ using an excitation pulse 
of $(\pi / 6)$ of $3.4 \mu$ s and a recycle delay of $2 \mathrm{~s} .{ }^{31} \mathrm{P}\left\{{ }^{1} \mathrm{H}\right\}$ NMR was recorded at $161.92 \mathrm{MHz}$ using an excitation pulse of $(\pi / 6)$ of $3.6 \mu$ s and a recycle delay of $2 \mathrm{~s}$ using WALTZ-16 ${ }^{1} \mathrm{H}$ decoupling during acquisition. Chemical shifts were referenced to tetramethylsilane (TMS). HRMS were recorded on a Bruker microTOF instrument operating in the positive mode. Infrared spectra were recorded on a Nicolet Avatar 320 FT-IR fitted with a Smart Golden Gate ${ }^{\mathrm{TM}}$ and UV-visible spectra on a Perkin Elmer LAMBDA 35 ${ }^{\mathrm{TM}}$ spectrophotometer. Melting points were determined with a BI Barnstead Electrothermal Ltd melting point apparatus and are uncorrected. Computer simulations utilized Spartan ’18 software (43) and were carried out on a 6-Core Mac Pro running 3.5 GHz Intel Xeon E5 processors in parallel.

\section{General synthesis}

4'-Aminobenzo-15-crown-5 (5 mmol) was dissolved in dry dichloromethane (50 ml) and the appropriate isocyanate or isothiocyanate $(5 \mathrm{mmol})$ dissolved in dry dichloromethane $(10 \mathrm{ml})$ was added with vigorous stirring under $\mathrm{N}_{2}$. The reaction mixture was stirred for a further $2 \mathrm{~h}$ to ensure complete formation of the corresponding urea or thiourea derivative before the solvent was removed under vacuum. The products were recrystallized from acetonitrile, isolated by filtration and air dried.

1a was obtained as a white powder. Yield: $330 \mathrm{mg}(96 \%) ;{ }^{1} \mathrm{H} \mathrm{NMR}\left(\mathrm{CDCl}_{3}\right) \delta$ : 7.31 (s, 1H, NH), 7.29 (s, 1H, NH), 7.25 (m, 3H, Ar), 7.15 (q, 2H, J = $8.4 \mathrm{~Hz}, \mathrm{Ar}), 6.99$ (s, 1H, Ar), 6.68 (s, 2H Ar), 4.03 (s, 2H, crown), 3.94, (s, 2H, crown), 3.87 (s, 2H, crown), 3.80 (s, 2H, crown), 3.75 (m, 8H, crown), 2.23 (s, 2H, NH); ${ }^{13} \mathrm{C} \mathrm{NMR}\left(\mathrm{CDCl}_{3}\right) \delta: 153.0$, 149.5, 144.2, 139.6, 134.0, 128.7. 122.0, 118.5, 115.5, 111.0, 106.2, 70.8, 70.7, 70.4, 70.2, 69.9, 69.6, 69.2, 68.7; m. p. $168-169^{\circ} \mathrm{C}$; IR (cm $\left.{ }^{-1}\right): 3300(\mathrm{~N}-\mathrm{H}), 1640(\mathrm{C}=\mathrm{O})$; m.p. 168-169 ${ }^{\circ}$, ESI HRMS m/z found: 425.1747, calculated: 425.1616 [M + Na $]^{+}$. 
1b was obtained as a grey-purple powder. Yield: $339 \mathrm{mg}(96 \%) ;{ }^{1} \mathrm{H} \mathrm{NMR}\left(\mathrm{CDCl}_{3}\right) \delta$ : 7.83 (s, 1H, NH), 7.78 (s, 1H, NH), 7.40-7.36 (m, 4H, Ar), 7.27-7.23 (m, 1H, Ar), 6.94 (s, 1H, Ar), 6.86 (t, $J=10.0 \mathrm{~Hz}, 2 \mathrm{H}, \mathrm{Ar}$ ), 4.12 (m, 4H, crown), 3.90 (m, 4H, crown), 3.75 (m, 8H, crown); ${ }^{13} \mathrm{C} \mathrm{NMR}\left(\mathrm{CDCl}_{3}\right) \delta: 180.3,149.8 .149 .5,137.5,130.0,129.3$, 126.8, 125.1, 118.6, 114.3, 112.1, 71.1, 71.1, 70.5, 70.4, 69.5, 69.4, 69.3. 69.0; IR (cm 1): $3284(\mathrm{~N}-\mathrm{H}), 1644$ (C=S); m. p. 131-134 C; ESI HRMS m/z found: 441.1632, calculated: $441.1460[\mathrm{M}+\mathrm{Na}]^{+}$.

1c was obtained as a yellow powder. Yield: $360 \mathrm{mg}(98 \%) ;{ }^{1} \mathrm{H}$ NMR (CDCl $/$ DMSOd6) $\delta: 9.03(\mathrm{~s}, 1 \mathrm{H}, \mathrm{NH}), 8.40(\mathrm{~s}, 1 \mathrm{H}, \mathrm{NH}), 8.12(\mathrm{~d}, J=4.4 \mathrm{~Hz}, 2 \mathrm{H}, \mathrm{Ar}), 7.65$ (d, $J=4.6$ Hz, 2H, Ar), 7.28 (s, 1H, Ar), 6.82 (t, $J=10.6$ Hz, 2H), 4.14-4.07 (m, 4H, crown), 3.883.84 (m, 4H, crown), 3.70 (m, 8H, crown); ${ }^{13} \mathrm{C}$ NMR (CDCl $3 / \mathrm{DMSO}^{\left.-\mathrm{d}_{6}\right)} \delta: 152.2$, 149.3, 146.4, 144.6, 141.3, 133.8, 124.8, 117.3, 115.2, 111.4, 106.4, 70.6, 70.6, 70.2, 70.1, 69.6, 69.4, 69.2, 68.7; IR ( $\left.\mathrm{cm}^{-1}\right)$ : $3346(\mathrm{~N}-\mathrm{H}), 1713(\mathrm{C}=\mathrm{O}), 1659,1324\left(\mathrm{NO}_{2}\right)$; m. p. $170-172^{\circ} \mathrm{C}$; ESI HRMS m/z found: 486.1177 , calculated: $486.2625[\mathrm{M}+\mathrm{K}]^{+}$.

1d was obtained as a yellow powder. Yield: $386 \mathrm{mg}(88 \%) ;{ }^{1} \mathrm{H}$ NMR (CDCl $3 / \mathrm{DMSO}-$ d $\left.{ }_{6}\right) \delta: 10.00(\mathrm{~m}, 1 \mathrm{H}, \mathrm{NH}), 9.80(\mathrm{~m}, 1 \mathrm{H}, \mathrm{NH}), 8.13(\mathrm{~d}, J=4.0 \mathrm{~Hz}, 2 \mathrm{H}, \mathrm{Ar}), 7.91-7.88$ (d, $J=4.4 \mathrm{~Hz}, 2 \mathrm{H}, \mathrm{Ar}), 7.19$ (s, 1H, Ar), 6.93-6.86 (m, 2H, Ar), 4.12-4.07 (m, 4H, crown),

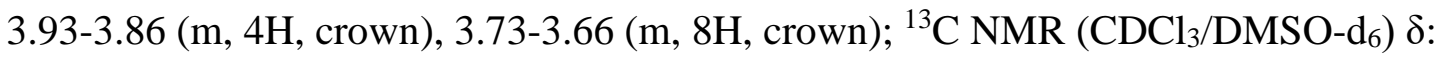
179.3, 148.7, 146.7, 123.8, 121.4, 113.8, 111.3, 70.5, 70.0, 69.9, 69.0, 69.0, 68.9, 68.6; IR (cm $\left.{ }^{-1}\right): 3300(\mathrm{~N}-\mathrm{H}), 1550\left(\mathrm{NO}_{2}\right)$; m. p. $187-189^{\circ} \mathrm{C}$; ESI HRMS m/z found: 486.1275, calculated: $486.1311[\mathrm{M}+\mathrm{Na}]^{+}$. 


\section{Computational chemistry}

All compounds were created using the 'Build' option in Spartan '18 and subjected to conformational analysis followed by molecular mechanics (using the Merck Molecular Force Field) to generate a structure for higher level calculations. Complexes of $\mathbf{1 c}$ and 1d with tetrabutylammonium fluoride, GD and the simulants were formed by importing the crown ether hosts and guests using the 'Minimizer' option followed by full conformational analysis to generate their initial structures. All complexes were initially modelled by semiempirical methods (PM6) in the gas phase which, in our experience, represent an excellent compromise between calculation time and accuracy for 'hostguest' complexes of this nature (44). Subsequent refinement using DFT methods (B3LYP/6-31G*) gave the structures illustrated.

Acknowledgements: PJC thanks the US Army Research Office (Contract W911NF-151-0624) for funding computational chemistry resources. MRS thanks Dr James Jones and Dr Rebecca Williams (Dstl) and the CBR Division NMR facility for NMR support.

Content includes material subject to (C) Crown copyright (2019), Dstl. This material is licensed under the terms of the Open Government Licence except where otherwise stated. To view this licence, visit http://www.nationalarchives.gov.uk/doc/opengovernment-licence/version/3 or write to the Information Policy Team, The National Archives, Kew, London TW9 4DU, or email: psi@nationalarchives.gov.uk. No potential conflict of interest exists. 


\section{References}

1. Rice, H.; Dalton, C.H.; Price, M.E.; Graham, S.J.; Green, A.C.; Jenner, J.;

Groombridge, H.J., Timperley, C.M. Proc. R. Soc. A, 2015, 471, 20140891

2. Yuki, H.; Hough, M.; Sageman, M.; Danzig, R.; Kotanic, R.; Leighton, T. Aum

Shinrikyo: Insights Into How Terrorists Develop Biological and Chemical Weapons,

Center for a New American Security, http://www.cnas.org, 2011

3. Black, R.M.; Read, R.W. Toxin Reviews, 2008, 26, 275-298.

4. Kim, K.; Tsay, O. G.; Atwood, D. A.; Churchill, D. G. Chem. Rev., 2011, 111, 53455403.

5. Sambrook, M. R.; Notman, S. Chem. Soc. Rev., 2013, 42, 9251-9267.

6. Hartmann-Thompson C.; Hu J.; Kaganove, S. N.; Keinath, S. E.; Keeley, D. L.;

Dvornic, P. R. Chem. Mater., 2004, 16, 5357-5364.

7. Sambrook M.R.; Hiscock, J. R.; Cook, A.; Green, A. C.; Holden. I.; Vincent, J. C.;

Gale, P. A. Chem. Commun., 2012, 48, 5605-5607.

8. Hiscock, J. R., Piana, F.; Sambrook, M. R.; Wells, N. J.; Clark, A. J.; Vincent, J. C.;

Busschaert, N.; Brown, R. C. D.; Gale, P. A. Chem. Commun., 2013, 49, 9119-9121.

9. Hiscock, J. R.; Wells, N. J.; Ede, J. A.; Gale, P. A.; Sambrook, M. R. Org. Biomol.

Chem. 2016, 14, 9560-9567

10. Ha, S.; Lee, M.; Seo, H. O.; Song, S. G.; Kim, K.-s.; Park, C. H.; Kim, I. H.; Kim, Y. D.; Song, C. ACS Sensors, 2017, 2, 1146-1151

11. Barba-Bon A.; Costero, A. M.; Parra, M.; Gil, S.; Martinez-Manez, R.; Sancenon, F.; Gale P. A.; Hiscock, J. R. Chem. Eur. J., 2013, 19, 1586-1590.

12. Jang, Y. J.; Tsay, O. G.; Murale, D. P.; Jeong, J. A.; Segev, A.; Churchill, D. A. Chem. Commun., 2014, 50, 7531-7534.

13. Gale. P. A.; Caltagirone C. Chem. Soc. Rev., 2015, 44, 4212-4227 
14. Nie, G.; Sun, Y.; Zhang, F.; Song, M.; Tian, D.; Jiang, L.; Li, H. Chem. Sci., 2015, 6, 5859-5865,

15. Bregović, V.B.; Basarić, N.; Mlinarić-Majerski, K. Coord. Chem. Rev., 2015, 295, 80-124.

16. Chansaenpak K.; Kamkaew, A.; Weeranantanapan, O.; Suttisintong , K.;

Tumcharern, G. Sensors, 2018, 18, 2042.

17. Munro, N. B.; Talmage, S. S.; Griffin, G. D.; Waters, L. C.; Watson, A. P.; King, J.

F.; Hauschild, V. Environ. Health Perspect., 1999, 107, 933-974.

18. Ágai, B.; Bitter, I.; Csongor, É.; Tőke, L. Acta Chim. Acad. Scient. Hung., 1982, 110, 25-28.

19. Amendola, V.; Esteban-Gómez,D.; Fabbrizzi, L.; Licchelli, M.; Monzani, M.;

Sancenón, F. Inorg. Chem., 2005, 44, 8690-8698.

20. Lee, J.H.; Lee, J.H.; Choi, Y.R.; Kang, P.; Choi, M.-G.; Jeong, K.-S. J. Org. Chem., 2014, 79, 6403-6409.

21. Piątek, P. Chem. Commun., 2011, 47, 4745-4747.

22. Akhuli, B.; Ghosh, P. Chem. Commun., 2015, 51, 16514-16517.

23. Mäkelä, T.; Kalenius, E.; Rissanen, K. Inorg. Chem., 2015, 54, 9154-9165.

24. Ziach, K.; Karbarz, M.; Romanski, J. Dalton Trans., 2016, 45, 11639-11643.

25. Makela, T.; Kiesila, A.; Kalenius, E.; Rissanen, K. Chem. Eur. J., 2016, 22, 1426414272

26. Ziach, K.; Jurczak, J.; Romanski, J. Inorg. Chem. Commun., 2017, 84, 251-254.

27. Jagleniec, D.; Siennicka,S.; Dobrzycki, Ł.; Karbarz, M.; Romański. J. Inorg. Chem., 2018, 57, 12941-12952.

28. Sambrook, M. R.; Vincent, J. C.; Ede, J. A.; Gass, I. A.; Cragg, P. J. RSC Advances, 2017, 7, 38069-38076. 
29. Zimmermann, C.; Mazein, P.; Rebiére, D.; Déjous, C.; Pistré, J.; Planade, R. IEEE Sens. 2004, 4, 479-488.

30. Long, Y.; Wang, Y.; Du, X.; Cheng, L.; Wu, P.; Jiang, Y. Sensors, 2015, 15, 18302-18314.

31. Hiscock, J. R.; Sambrook, M. R.; Ede, J. A.; Wells, N. J.; Gale, P. A. J. Mater. Chem. A, 2015, 3, 1230-1234.

32. Barboiu, M.; Vaughan, G.; van der Lee, A. Org. Lett., 2003, 5, 3073-3076.

33. Boiocchi, M.; Del Boca, L.; Esteban-Gómez, D.; Fabbrizzi, L.; Licchelli, M.;

Monzani, E. J. Am. Chem. Soc., 2004, 126, 16507-16514.

34. Jose, D. A.; Kumar, D. K.; Ganguly, B.; Das, A. Org. Lett., 2004, 6, 3445-3448.

35. Esteban-Gómez, D.; Fabbrizzi, L.; Licchelli, M. J. Org. Chem., 2005, 70, 57175720.

36. Saikia, E.; Borpuzari, M. P.; Chetia, B.; Kar, R. Spectrochim. Acta A: Mol. Biomol. Spectr., 2016, 152, 101-108.

37. Kirby, I. L.; Pitak, M. B.; Wilson, C.; Gale P. A.; Coles, S. J. CrystEngComm., 2015, 17, 2815-2826.

38. McLain, S. E.; Benmore, C. J.; Siewenie, J. E.; Urquidi, J.; Turner, J. F. C. Angew. Chem. Int. Ed., 2004, 43, 1952-1955.

39. Hynes, M. J.; J. Chem. Soc. Dalton Trans. 1993, 311.

40. Caltagirone, C.; Hiscock, J.R.; Hursthouse, M.B.; Light, M.E.; Gale, P.A., Chem. Eur. J. 2008, 14, 10236-10243.

41. Makuc, D.; Hiscock, J.R.; Light, M.E.; Gale, P.A.; Plavec, J. Beilstein J. Org. Chem. 2011, 7, 1205-1214.

42. Lavoie, J.; Srinivasan, S.; Nagarajan, R. J. Hazard. Mater., 2011, 194, 85-91.

43. Spartan '18, Wavefunction, Inc., Irvine, CA 92612-8542, USA. 
44. Sheehan R.; Cragg, P. J. Supramol. Chem., 2008, 20, 443-451. 